\title{
Phenomena in Frozen Valves from A Valve Bank
}

\author{
Maciej Pawlikowski* \\ Department of Mineralogy, Petrography and Geochemistry, AGH - University of Science and Technology, Poland
}

*Corresponding author: Maciej Pawlikowski, Department of Mineralogy, Petrography and Geochemistry, AGH - University of Science and Technology, Poland

\begin{abstract}
Studies were conducted on valves from a valve bank, frozen for up to 19 years. Obtained results were compared to studies of fresh, non-frozen valves. Stereomicroscopy, polarized light microscopy, scanning microscopy and X-ray diffractometry were used in the studies. It was determined that the structures of valve leaflets after prolonged freezing time (4-5 years) do not return to their initial, pre-frozen state. Changes in the structures after freezing time of over 5 years may, when the valves are implemented, favor faster damage processes, including calcification. Hence it appears beneficial to only implant valves that have been frozen for less than 5 years.
\end{abstract}

Keywords: Heart Valves; Freezing

\section{Introduction}

Phenomena occurring in the heart, including its valves, may be connected to their biomineralization, commonly known as "calcification" [1-4]. Calcification is recognized using many methods [5-13]. Early and comprehensive diagnosis of changes in the heart is important; particularly essential is the choice of methods of recognizing calcification in specific parts of the heart - especially the valves and coronary vessels [14-21]. Recognition of the level of development of that phenomenon and the influence of the factors causing the calcification is the basis for choosing the right treatment method [20,22-25]. Particularly interesting are problems of valve mineralization, which causes a series of disorders not only of the heart but the whole circulatory system [26-30]. That is why, in addition to the pharmacological treatment [31-33], the choice of the right surgery technique and the right valve prosthesis [13, 34$40]$ is essential. One of the options is a frozen valve from a heart valve bank. This publication discusses some aspects of freezing heart valves and changes in the structures of frozen valves [41].

\section{Materials and Methods}

The material for research was gifted by prof. Dr hab. Roman Pfitzner from the John Paul II Hospital in Krakow, whom the author would like to offer sincere thanks. The studies were conducted on valve leaflets after the following periods of freezing altogether 19 valves: a) Valves frozen in 2002 (15 years). Samples number 18731925.

b) Valves frozen in 2003 (13-14 years). Samples number 19281948.

c) A valve frozen in 2005 (12 years). Sample number 2031.

d) Valves frozen in 2009-2011 (9-10 years). Samples number $2149-2177$.

e) Samples frozen in 2014-2015 (4-5 years, according to standards). Samples number 2232-2249.

f) Fresh valves, not frozen. Samples number 2290 and 2292.

The author's gratitude goes also to Mr. Adam Gaweł, MSci, for conducting X-ray analyses and results descriptions.

\section{a) Digital Microscope}

Preparations made from valves were examined using the Motic microscope of Chinese production, model 07-100477, with side light. Observations were made at various magnifications. Identified objects and phenomena were documented with photomicrographs using a Canon camera with a 20 MP matrix.

\section{b) Scanning Microscope with EDS Detector}

FEI Quanta 200 FEG microscope was used in the examinations. 
They were conducted in the "Low Vacuum" mode, using cathodic voltage of $10 \mathrm{KV}$. Observed phenomena were documented with photomicrographs.

\section{c) X-Ray Diffractometry}

A Philips device with a vertical goniometer was used. $\mathrm{Cu} \mathrm{K \alpha}$ radiation was used. Calculations of the dhkl values for individual reflexes were done based on X-ray data tables.

\section{Results of Microscopic Studies}

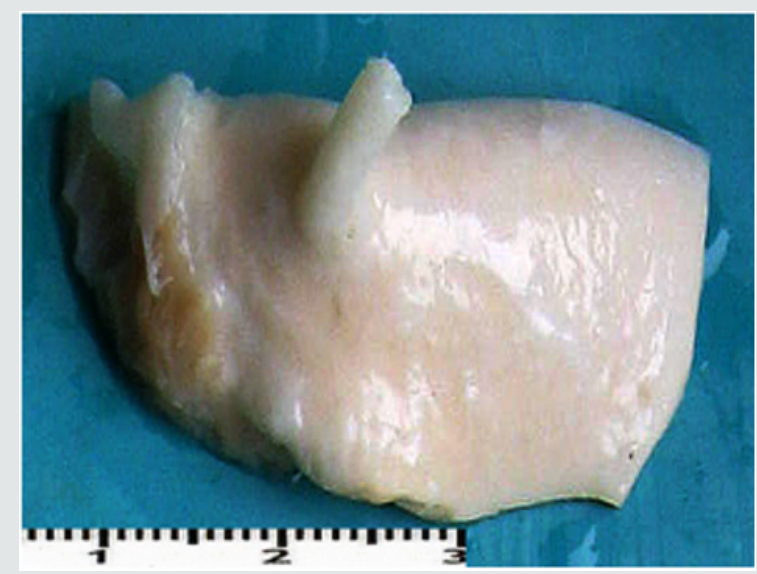

Photo 1(a): Sample photos of studied valves. A - fragment of a valve (sample 1925) after 15 years in deep freeze.

Macroscopic observations of the valve leaflets morphology showed that valves kept in deep freeze even for a long time do not differ from fresh valves (Photo 1). That suggested their full suitability for implementation. However, observations of the leaflets' surface conducted in higher magnifications reveal a lot of details, including differences in the appearance of the valve leaflets' surface. Apart from the visible differences resulting from the leaflets' structure, especially the layout of the collagen fibers (Photo 2(a)), defects connected with the process of harvesting the material for the valve bank are visible on the surface of some leaflets. The damaged spots are potential centers for calcification development (Photo 2(b)). Some of the defects are visible only in high magnification. With long-time freezing, they may favor deformation of collagen strands, which in result may shorten the time of correct functioning of the valve after being implemented. Observations of the valve leaflets under scanning microscope show that leaflets of the valves that have been frozen for a long time have, after defreezing, deformed structure of collagen fibers (Photo 3(a) $\& 3(b))$. The degree of deformation depends on the freezing time (Photo 3(c) \& 3(d)). Valves kept in deep freeze for a period of up to 5 years are almost unchanged or minimally changed structurally. Conducted observations also show that structural changes of the valve leaflets connected with long period of freezing affect not just the surface but also the fibrosa of the valves. It is visible in crosssections of the leaflets (Photo 4(a) \& 4(b)). Leaflets of valves that have been frozen for a long-time show, after thawing and in crosssection, separation of collagen fibers and often even their breaking.
That means deterioration of physical parameters of the leaflets, which may result in worse efficiency of the valve made of that material.

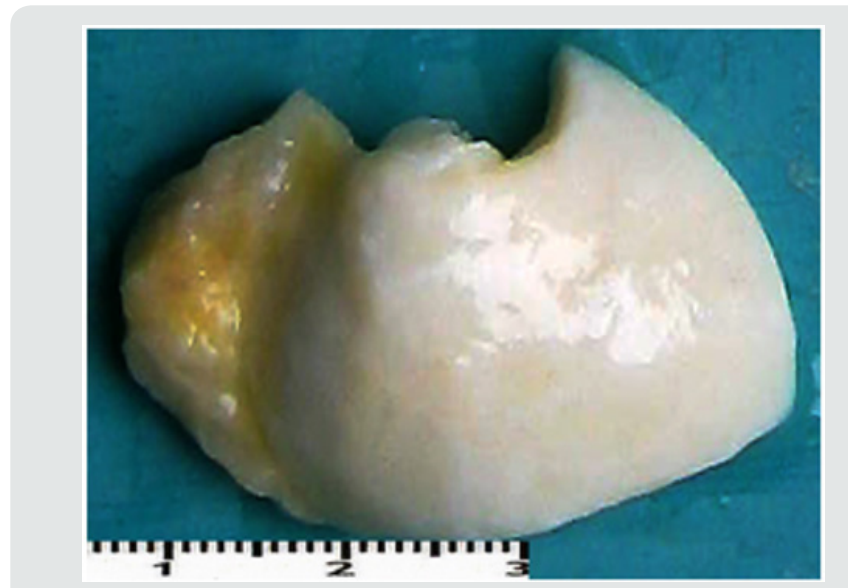

Photo 1(b): fragment of a fresh (not frozen) valve (comparison material).

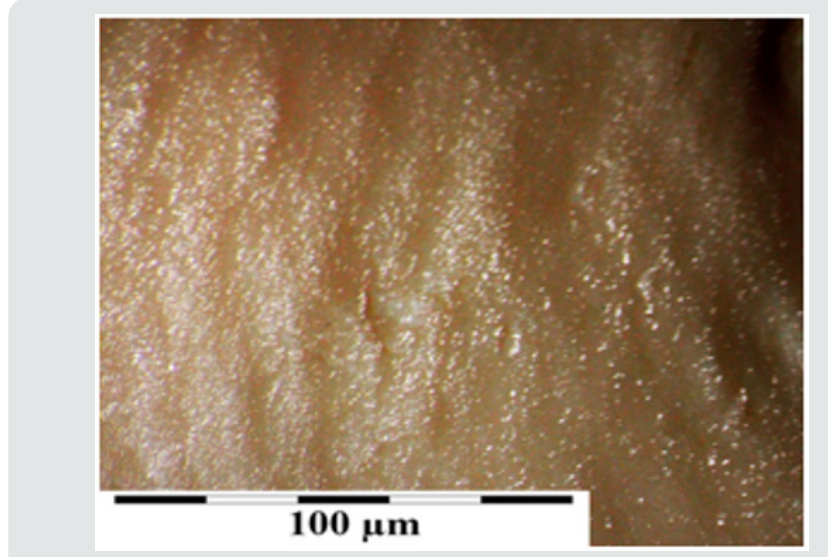

Photo 2(a): Sample photos of the surface of valve leaflets. Sample of the leaflet of a valve frozen for 15 years (sample 1925) with visible bundles of collagen fibers.

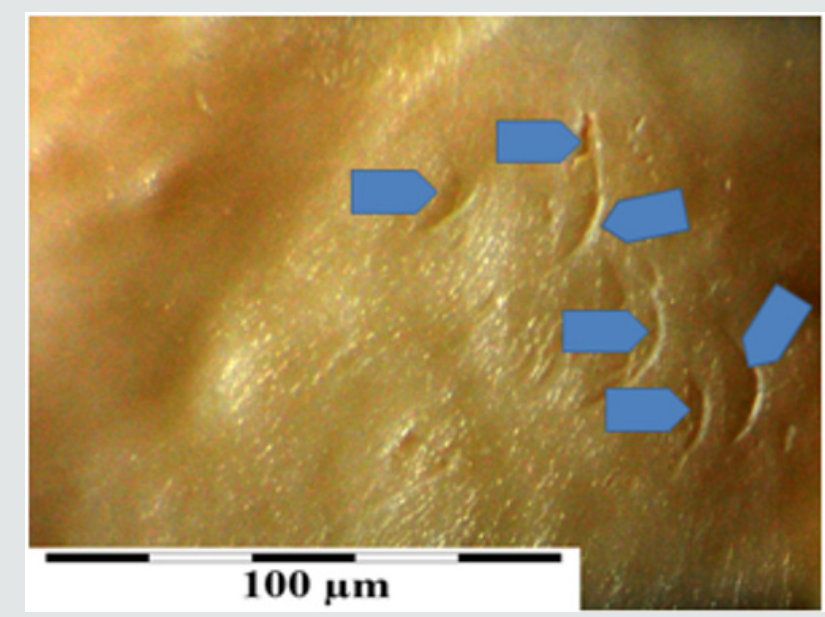

Photo 2(b): Surface of a valve leaflet (sample 2990) from a fresh, not frozen valve (comparison material). Arrows show places of damage from the process of valve harvesting. 


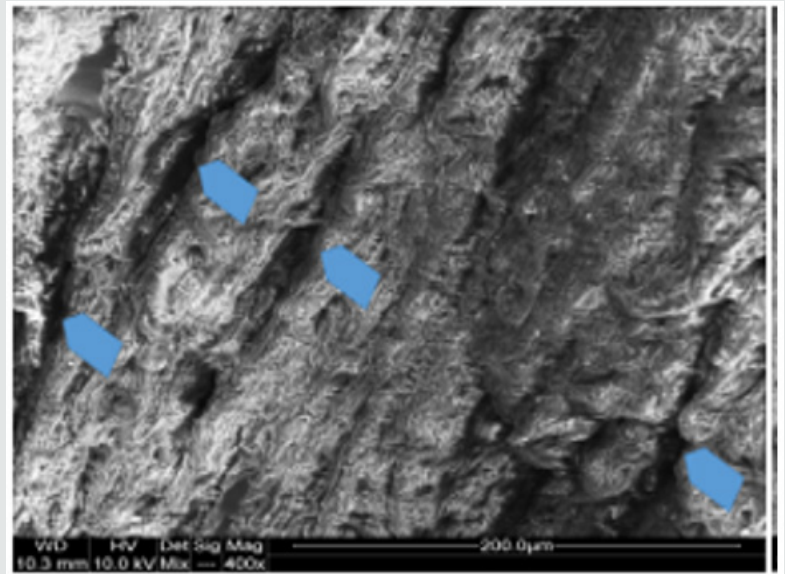

Photo 3(a): Sample photos of the surface of examined valves. Valve frozen for 15 years.

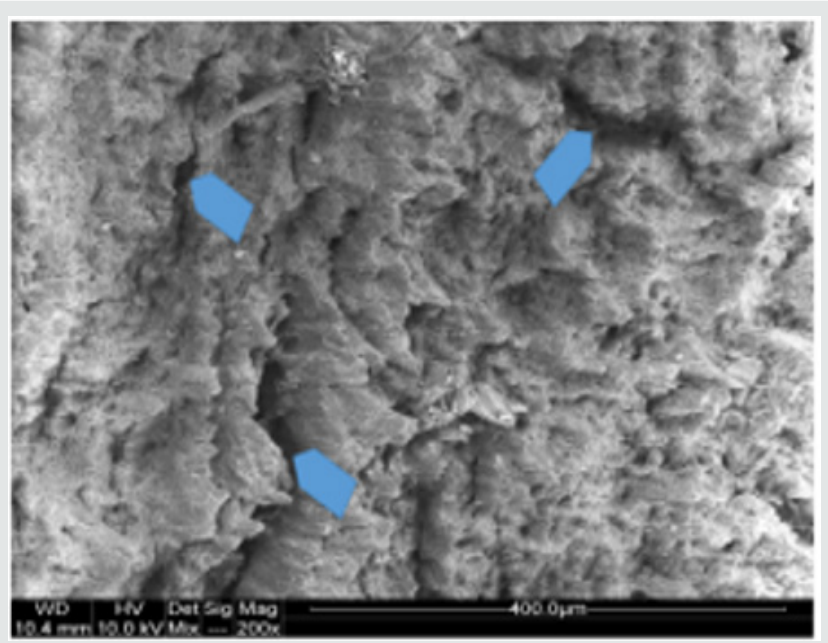

Photo 3(b): Valve frozen for 13 years.

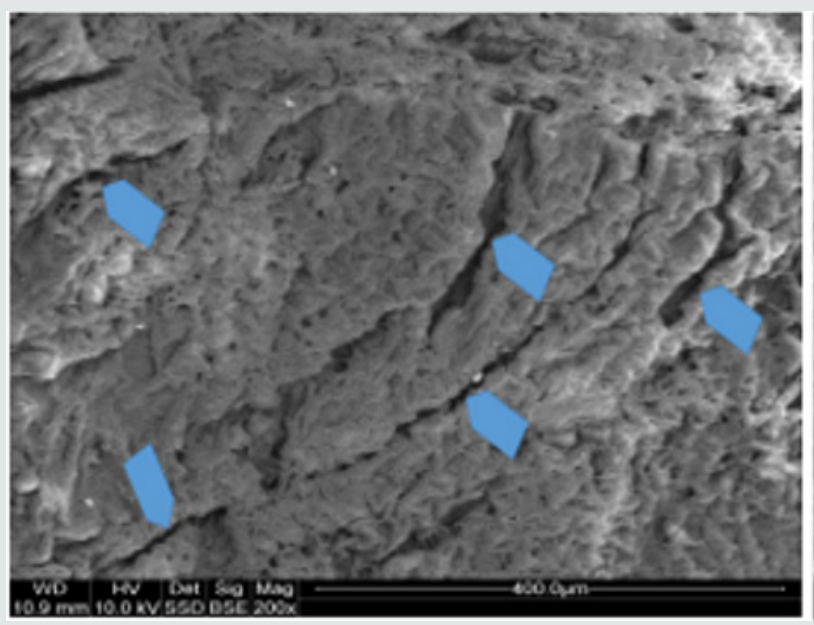

Photo 3(c): Valve frozen for 12 years.

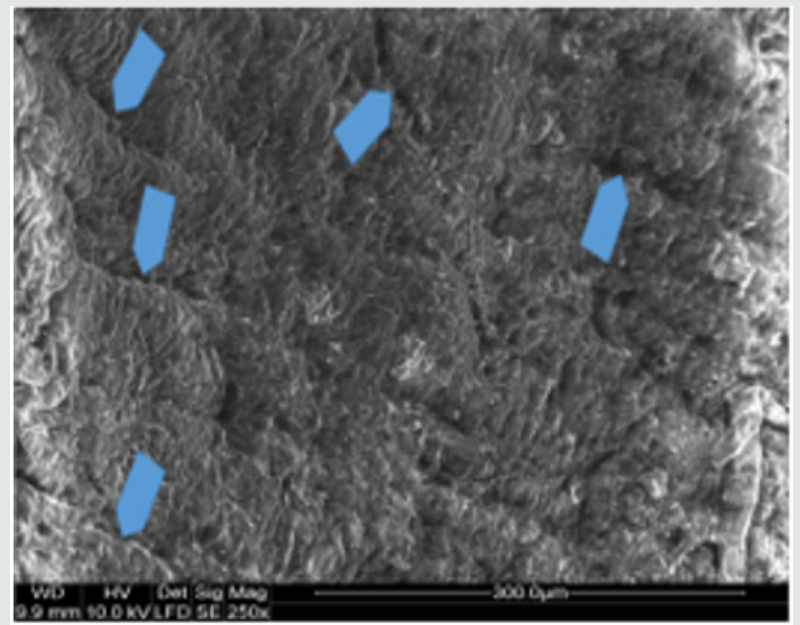

Photo 3(d): Valve frozen for 10 years.

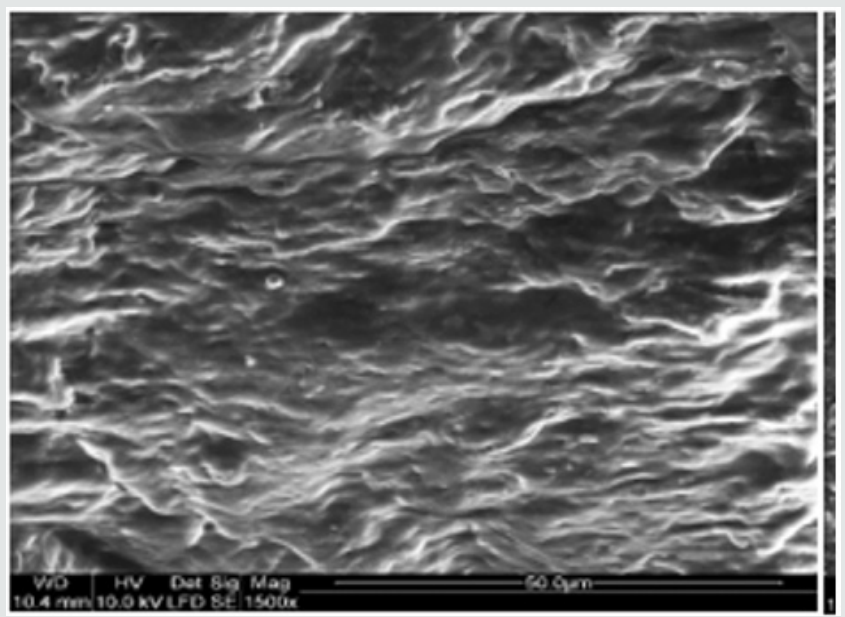

Photo 3(e): Fresh valves - comparison material. SEM.

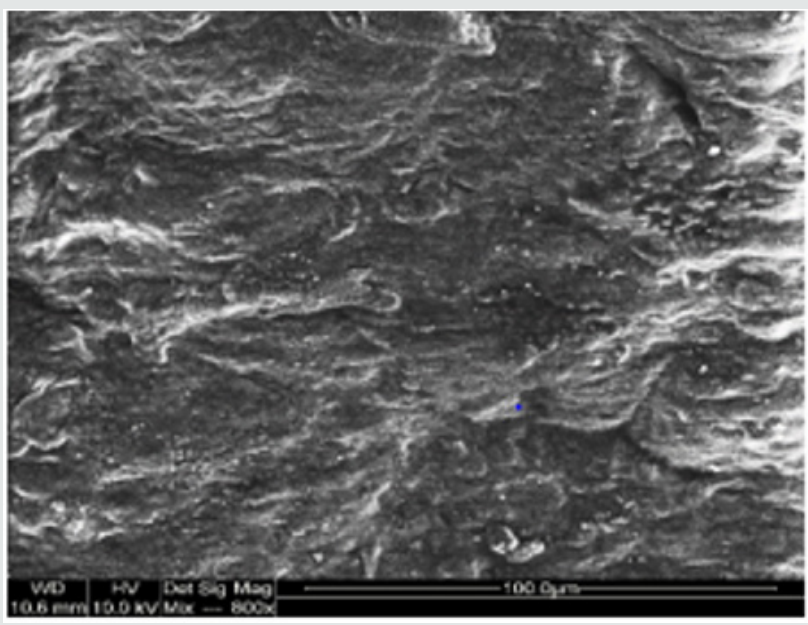

Photo 3(f): F - fresh valves - comparison material. SEM. 


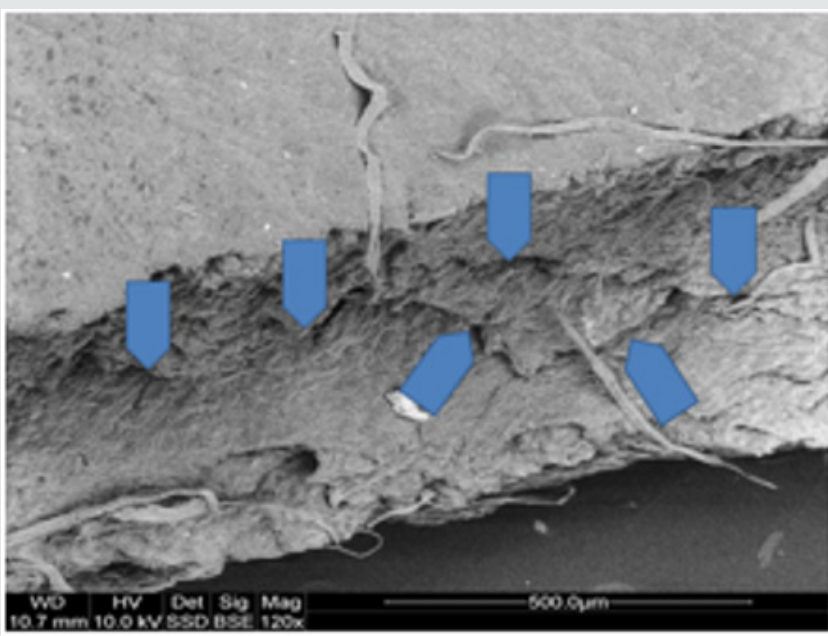

A

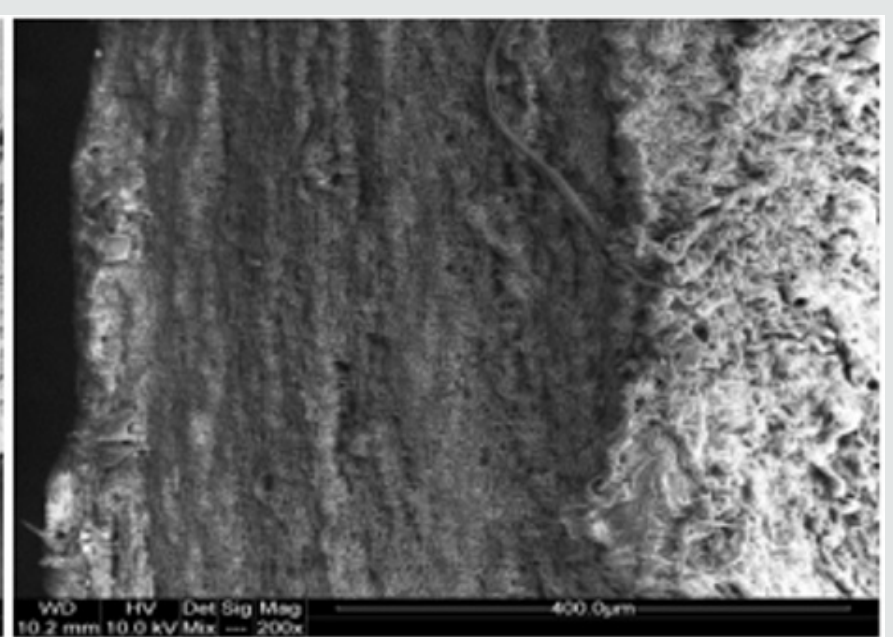

B

Photo 4: Sample photos of chosen valves in cross-section. A - cross section of a valve frozen for 12 years. Visible defects in valve fibrosa (arrows). B - fresh valve - comparison material. SEM.

\section{Results of Structural X-Ray Diffractometry}

The goal of X-ray examination was to recognize phenomena in the valve collagen depending on the period of freezing. From each of the valves (from a leaflet) a $1 \mathrm{~cm}$ by $1 \mathrm{~cm}$ square was cut and placed on the diffractometer head. The measuring was done within 0-75o 29, obtaining a series of diffractograms (Figure 1). Despite seemingly identical character of the diffractograms, shifting of the diffused strand coming from water was observed, from 27o $2 \theta$ to 30 o $2 \theta$ with increasing time of valve freezing (Figure 1). Described phenomenon indicates changing way of bonding water by the collagen structures of the valves with increasing freezing time. That phenomenon may be the result of deformation of collagen structure with prolonged time of valve freezing. On X-ray diffractograms of water present in the valves (Figure 1), it manifests with shifting of the maximum of the stronger diffused reflection from dhkl around $3,32 \AA$ to dhkl around $2.70 \AA$ with the increasing time of valve freezing. Changes in this value may indicate shortening of interatomic bonds in collagen. Simply speaking, they indicate change of the structure of valve collagen after a prolonged time of valve freezing. That phenomenon in turn suggests that valves that have been frozen for a long time may be less durable in the recipient's body. Structural X-ray diffractometry of pure collagen conducted at the same time shows that (Figure 2) in addition to a strong peak of dhkl $=9.07 \AA$, which is also visible on the diffractograms of valves (Fig. 1), collagen gives a diffused band with heightened background within dhkl 7,37 $\AA$ - $3.08 \AA$. It hides under bigger and stronger band of water observed in valve diffractograms between dhkl 2.70-3,32 Å. Such situation impedes direct recognition by the X-ray method of structural changes in collagen connected with freezing. Hence the considerations regarding change of the structure of valve collagen connected with the freezing process are deductive in nature and are based only on observations related to structural changes in water bound by collagen of the frozen valves.

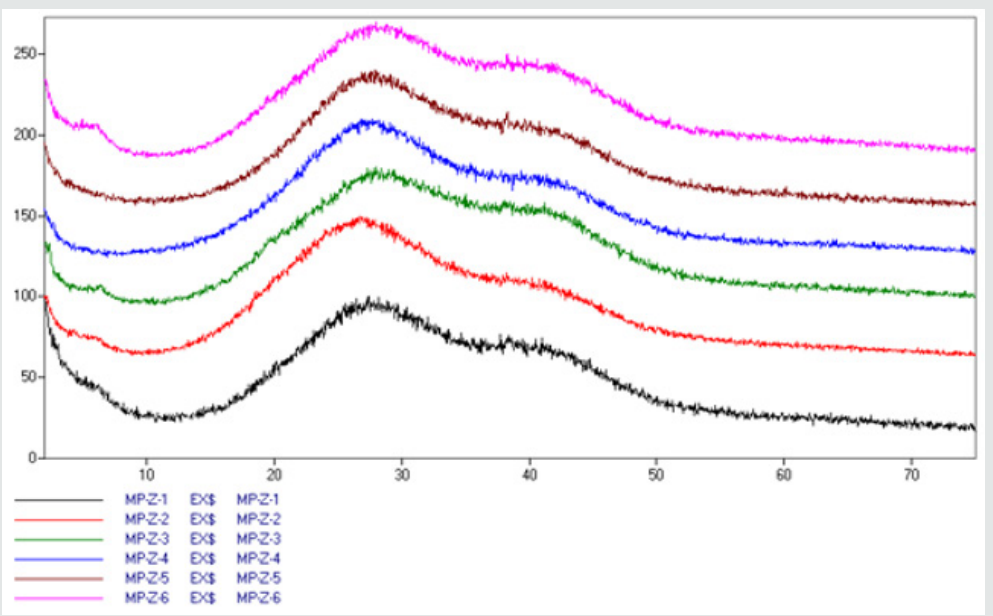

Figure 1: X-ray diffractograms of valve leaflets, presented from the bottom: $Z$ - valve frozen for 15 years, Z5 - valve frozen for 5 years, Z6 - fresh valve. Visible oscillation of position and intensity of collagen peak $(5 \circ 2 \theta)$ and change of position of maximum diffused water peak from $27 \mathrm{o} 2 \theta$ to $30 \mathrm{o} 2 \theta$ with the increasing time of valve freezing. 


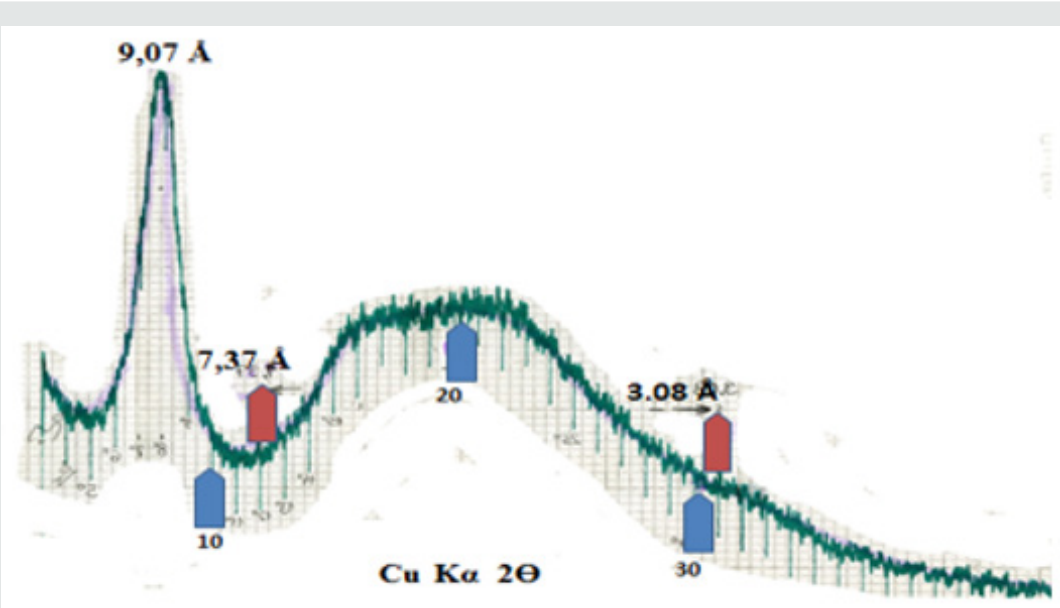

Figure 2: X-ray diffractogram of pure collagen.

\section{Conclusion}

SEM research indicates that deformation of collagen fibers in the valves takes place along with prolonged freezing time. Collagen fibers (in valves) frozen for a long time at a temperature of liquid nitrogen do not return to their original size after thawing. This affects the fiber length reduction to a smaller extent than their width. It results in the formation of micro-spacing between fibers, which after implantation, as a place with electric charges, may undergo calcification processes (biomineralization). Structural studies carried out using the X-ray diffractometry method indicate that long-term freezing promotes deformation of the structure of the collagen building the valve fibers, in addition to the deformation of the structure of collagen fibers. This is observed on X-ray diffractograms as a modified way of water binding on the surface of the valve leaflets kept for a long time in the frozen state. The obtained results can be "translated" into practical suggestions for transplants of allogeneic, frozen valves. They indicate that it is unfavorable to store the valves in freezing for a period longer than 4-5 years. Longer freezing of the valves causes changes that favor disadvantageous functioning of transplants.

\section{References}

1. Bloomfield P (2002) Choice of heart valve prosthesis. Heart 87: 583-589.

2. Harbaoui B, Montoy M, Charles P, Boussel L, Liebqott H, et al. (2016) Aorta calcification burden: towards an integrative predictor of cardiac outcome after transcatheter aortic valve implantation. Atherosclerosis 246: 161-168.

3. Herzog CA, Ma JZ, Collins AJ (2002) Long-term survival of dialysis patients in the United States with prosthetic heart valves. Should ACC/ AHA practice guidelines on valve selection be modified? Circulation 05: 1336-1341.

4. Piper C, Körfer R, Horstkotte D, (2000) Prosthetic valve endocarditis. Heart 85: 590-593.

5. Bertazzo S, Gentleman E, (2007) Aortic valve calcification: a bone of contention. Eur Heart J 38(16): 1189-1193.

6. Khetarpal V, Mahajan N, Madhavan R, Batra S, Mopala P, et al. (2009) Calcific aortic valve and spontaneous embolic stroke: a review of literature. J Neurol Sci 287(1-2): 32-35.
7. Koos R, Mahnken AH, Dohmen G, Brehmer K, Gunther RW et al. (2011) Association of aortic valve calcification severity with the degree of aortic regurgitation after transcatheter aortic valve implantation. Int J Cardiol 150: $142-145$.

8. Lindroos M, Kupari M, Valvanne J, Strandberg T, Heikkila J, et al. (1994) Factors associated with calcific aortic valve degeneration in the elderly. Eur Heart J 15: 865-870.

9. Pawlikowski M (2018) Biomineralogical Phenomenon of Mineralization (Calcification) of Arteries. (1): 1-8.

10. Pawlikowski M, (2018) Problems of Biomineralization Dissolution in Human Arteries. Adv Card Res 1(4): 68-75.

11. Peter M, Hoffmann A, Parker C, Luscher T, Burckhardt D (1993) Progression of aortic stenosis: role of age and concomitant coronary artery disease. Chest 103: 1715-1719.

12. Ryś M, Hryniewiecki T, Michałowska I, Stokłosa P, Różewicz Juraszek M, et al. (2018) Quantitative estimation of aortic valve calcification in multislice computed tomography in predicting the development of paravalvular leaks following transcatheter aortic valve replacemen. Postepy Kardiol. Interwencyjnej 14(1): 85-89.

13. Sangiorgi G, Rumberger JA, Severson A, Edwards WD, Gregoire J, et al. (1998) Arterial calcification and not lumen stenosis is highly correlated with atherosclerotic plaque burden in humans: a histologic study of 723 coronary artery segments using nondecalcifying methodology. J Am Coll Cardiol 31: 126-133.

14. Takamiya Y, Miura S, Sako H, Shirai K, Morishige N, et al. (2007) Pseudoaneurysm of the mitral-aortic intervalvular fibrosa following infective endocarditis in a patient with acute heart failure: a case report. J Cardiol 49: 353-356.

15. Agatston AS, Janowitz WR, Hildner FJ, Zusmer NR, Viamonte M Jr, et al. (1990) Quantification of coronary artery calcium using ultrafast computed tomography. J Am Coll Cardiol 15: 827-832.

16. Boughner DR, Thornton M, Dunmore Buyze J, Holdsworth DW (2000) The radiographic quantitation of aortic valve calcification: implications for assessing bioprosthetic valve calcification in vitro. Physiol. Meas 21: 409-416.

17. Budoff MJ, Lane KL, Bakhsheshi H, Mao S, Grassmann BO, et al. (2000) Rates of progression of coronary calcium by electron beam tomography. Am J Cardiol 86: 8-11.

18. Kapila A, Hart R (1986) Hart calcific cerebral emboli and aortic stenosis: detection by computed tomography. Stroke $17:$ 619-621.

19. Kizer JR, Gefter WB, de Lemos AS, Scoll BJ, Wolfe ML, et al. (2001) Electron beam computed tomography for the quantification of aortic valve calcification. J. Heart Valve Dis 10: 361-366. 
20. Otto CM, Burwash IG, Legget ME, Munt BI, Fujioka M, et al. (1997) Prospective study of asymptomatic valvular aortic stenosis: clinical, echocardiographic, and exercise predictors of outcome. Circulation 95 2262-2270.

21. Pawlikowski M (2019) Biomineralization of Heart Valves. J Clin Rev Case Rep 4(2): 1-6.

22. Rumberger JA, Simons DB, Fitzpatrick LA, Sheedy PF, Schwartz RS (1995) Coronary artery calcium area by electron-beam computed tomography and coronary atherosclerotic plaque area: a histopathologic correlative study. Circulation 92: 2157-2162.

23. Callister TQ Raggi P, Cooil B, et al. (1998) Effect of HMG-CoA reductase inhibitors on coronary artery disease as assessed by electron-beam computed tomography. N Engl J Med 339: 1972-1978.

24. Mako WJ, Vesely I (1997) In vivo and in vitro models of calcification in porcine aortic valve cusps. J Heart Valve Disease 6(3): 316-323.

25. Pawlikowski M, Pfitzner R(1999) Mineralization of heart, (Mineralization of heart and big blood vessels). Wyd IGSMiE PAN Kraków, pp. 142.

26. Pfitzner R, Barecka D, Pawlikowski M, Kopytek M, Rudnicka Sosin, et al. (2018) Influence of cryopreservation on structural, chemical and immunoenzymatic properties of the aortic valve allografts. Transplantation Proceedings 50(7): 2195-2198.

27. Iivanainen AM, Lindroos M, Tilvis R, Heikkila J, Kupari M (1996) Calcific degeneration of the aortic valve in old age: is the development of flow obstruction predictable? J Intern Med 239: 269-273.

28. Khalique OK, Hahn RT, Gada H, Nazif TM, Vahl TP, et al. (2014) Quantity and location of aortic valve complex calcification predicts severity and location of paravalvular regurgitation and frequency of post-dilation after balloon-expandable transcatheter aortic valve replacement. JACC Cardiovasc Interv 7: 885-894.

29. Mohler ER (2000) Are atherosclerotic processes involved in aortic-valve calcification? Lancet 356: 524-525.

30. Otto CM, Lind BK, Kitzman DW, Gersh BJ, Siscovick DS (1999) Association of aortic-valve sclerosis with cardiovascular mortality and morbidity in the elderly. N Engl J Med 341: 142-147.

31. Pibarot P, Dumesnil JG (2000) Hemodynamic and clinical impact of prosthesis-patient mismatch in the aortic valve position and its prevention. J Am Coll Cardiol 36: 1131-1141.
32. Gohlke Barwolf C (2000) Anticoagulation in valvar heart disease: new aspects and management during non-cardiac surgery. Heart 84(5): 567572 .

33. Massel D, Little SH, (2001) Risks and benefits of adding anti-platelet therapy to warfarin among patients with prosthetic heart valves: a metaanalysis. J Am Coll Cardiol 37: 569-578.

34. Nagueh SF, Sun H, Kopelen HA, Middleton KJ, Khoury DS (2001) Hemodynamic determinants of the mitral annulus diastolic velocities by tissue Doppler. J Am Coll Cardiol 37: 278-285.

35. Ewe SH, Ng AC, SchuijfJD, Vander Kley F, Colli A, et al. (2011) Location and severity of aortic valve calcium and implications for aortic regurgitation after transcatheter aortic valve implantation. Am J Cardiol 108: 14701477.

36. Enriquez Sarano M (2002) Timing of mitral valve surgery. Heart 87: 7985.

37. Haensig M, Lehmkuhl L, Rastan AJ, Kempfert J, Mukherjee C, et al. (2012) Aortic valve calcium scoring is a predictor of significant paravalvular aortic insufficiency in Surg. 41: 1234-1240.

38. Kleczyński P, Dziewierz A, Daniec M, Bagienski M, Rzeszutko L, et al. (2017) Impact of post-dilatation on the reduction of paravalvular leak and mortality after transcatheter aortic valve implantation. Kardiol. Pol 75: $742-748$

39. Lindblom D, Lindblom U, Qvist J, Lundstrom H (2001) Long-term relative survival rates after heart valve replacement. J Am Coll Cardiol 15: 566-573.

40. Otto CM, Kuusisto J, Reichenbach D, Allen M Gown, Kevin D O Brien (1994) Characterization of the early lesion of "degenerative" valvular aortic stenosis: histological and immunohistochemical studies. Circulation 90: 844-853.

41. Stewart BF, Siscovick D, Lind BK, Gardin JM, Gottidiener JS, et al. (1997) Clinical factors associated with calcific aortic valve disease. J Am Coll Cardiol 29: 630-634.
(C) 7 This work is licensed under Creative

To Submit Your Article Click Here: Submit Article

DOI: $10.32474 /$ SCSOAJ.2019.02.000150

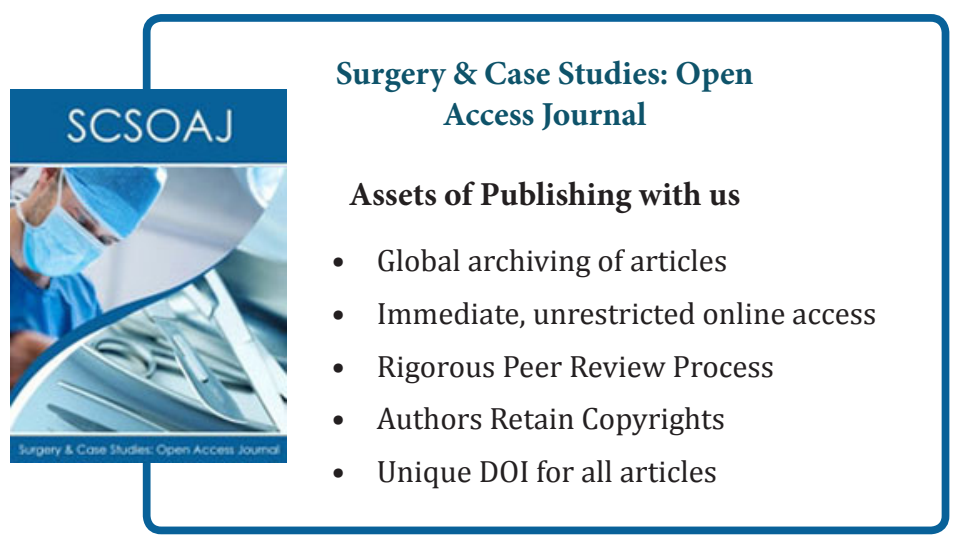

